\title{
REPERTORIUM VAN TIJDSCHRIFTLITERATUUR OP HET GEBIED VAN ACCOUNTANCY EN BEDRIJFSHUISHOUDKUNDE
}

\author{
Verschïnt maandelijks, bebalve in augustus. \\ Samengesteld door de Stichting voor Econo- \\ misch Onderzoek der Universiteit van Am- \\ sterdam
}

\section{B. BEDRIJFSHUISHOUDKUNDE}

\section{a. ALGEMENE BEDRIJFSHUISHOUDKUNDE}

\section{LEER VAN DE KOSTPRIJS EN DE PRIJSVORMING}

\section{Het fiscale winstbegrip}

Het julinummer van het Maandblad voor Accountancy en Bedrijfshuishoudkunde is gewijd aan het fiscale winstbegrip. Bijdragen zijn geleverd door:

M. A. Wisselink: Goed Koopmansgebruik. Wisselink behandelt het goed koopmansgebruik in het civiele contracten-recht, het fiscaal "goed koopmansgebruik" en het goed koopmansgebruik in maatschappelijke zin.

N. E. Auerbach: Principles and rules of income determination from the aspect of U.S. taxation. Teneinde een indruk te geven hoe in de Verenigde Staten het belastbare inkomen wordt vastgesteld, behandelt de schrijver naast de belastingstructuur een aantal begrippen, van belang bij belastingvraagstukken, zoals waardering van de inventaris, afschrijving, calculatiemethoden en scheiding van eenheid.

A. W. Clements: Economic and fiscal concepts of income in the United Kingdom. Clements behandelt het economische en fiscale winstbegrip in het Verenigd Koninkrijk, waarbij hij zich beperkt tot het bedrijfsinkomen.

J. Delattre: De la notion de revenus dans l'économie et la fiscalité française. De schrijver behandelt het voorgaande onderwerp voor Frankrijk.

W. Rijser: Réflexions sur la notion de bénéfice en droit fiscal et civil suisse. De schrijver beziet de oorzaken van de problemen bij het economische winstbegrip. Vervolgens behandelt hij het winstbegrip in het civiele recht en het fiscaal winstbegrip in $Z_{\text {witserland. }}$

R. Thiel: Der handelsrechtliche und steuerrechtliche Gewinnbegriff in der Bundesrepublik Deutschland. De schrijver behandelt het begrip bedrijfsinkomen zoals dat wordt gehanteerd door het bedrijfsleven, de accountant en de belastingdeskundigen.

D. A. M. Meeles: Het winstbegrip, fiscaal en economisch. De schrijver beziet in het kort het fiscale winstbegrip vanaf 1940 en sluit aan op Wisselink bij de behandeling van de rol van het financieringsmoment van de te betalen belastingen en aangaande het liquiditeitsprincipe. Hij wijst er tenslotte op dat bij het zoeken naar integratie van het liquiditeitsprincipe in het fiscale winstbegrip in het buitenland deels met gelijke middelen, deels met andere (genoemde) maatregelen wordt gewerkt.

Ba IV - 2e Maandblad voor Accountancy en Bedrïfshuishoudkunde, juli 1967 E 253

\section{De controverse rondom de lege N.V.}

Verburg, Mr. J. - Behandeld worden de maatregelen tegen misbruik bij het overnemen van lege n.v.'s met verrekenbare verliezen, waarbij de schrijver eerst ingaat op de arresten B.N.B. $1962 / 139$ en 292 , welke naar zijn mening niet mogen worden overschat als bestrijdingsmiddel omdat er sprake was van een gemis aan de vereiste voorzichtigheid.

Bij het arrest B.N.B. 1962/292 gaat de schrijver in op het verschil in opvatting tussen het gerechtshof te 's-Gravenhage en de Hoge Raad aangaande art. 18 lid 2, Besluit Vpb.

De mogelijkheden om voordeel te halen uit overneming van een n.v. met compensabele verliezen, welke mogelijkheden er volgens de schrijver nog steeds zijn, worden door het besproken art. 19 lid 7 van het ontwerp-Wet op de vennootschapsbelasting 1960 beperkt; in de I.B.-sfeer zijn ze echter nog wel aanwezig, ondanks B.N.B. 1962/139. Vervolgens beziet de schrijver of arrest B.N.B. 1959/64 (een lege n.v. is geen ontbonden n.v.) wordt miskend door B.N.B. 1962/206, waarin onder meer het voorschrijven van richtige-heffingsbepalingen. Via de richtige-heffingsbepalingen, waarop de schrijver ingaat aan de hand van een stelling in het proefschrift van A. L. Olde Kater komt hij tot de motivering van art. 19 lid 7 in de Memorie van Antwoord van de regering, waarin geen aandacht is geschonken aan de parlementaire behandeling van de Derde Titel van Boek 2, Nieuw Burgerlijk Wetboek. Daarbij werd onder meer bepleit het O.M. de bevoegdheid toe te kennen om de recht- 
bank ontbinding van een lege n.v. te verzoeken en tevens de wens geuit te bepalen dat een n.v. wordt ontbonden door opheffing van haar faillissement bij gebrek aan baten, hetgeen is gevolgd in de artikelen 2. 3.1.10a en 2. 3.6. 1. Hierbij is de rechtszekerheid verzekerd, aldus de schrijver, in het streven de lege n.v. uit de strijd te nemen.

Ba IV - 7 : VI - 14

Weekblad voor fiscaal recht, 29/6 - 6/7 1967

E $612.42: 251.2$

\section{LEER VAN DE ORGANISATIE}

\section{The Operational Research Approach}

Mo r e, P. G. - Operationele research houdt zich bezig met problemen, die ontstaan bij leiding en beheersing van grote organisaties van mensen, machines, materialen en geld. Men tracht een wetenschappelijk model van de organisatie te ontwikkelen, rekening houdend met factoren zoals kans en risico, om de uitkomsten van alternatieve beslissingen te voorspellen en te vergelijken. Een essentieel kenmerk van operationele research is de samenwerking in teamverband van personen die vanuit verschillende, wetenschappelijke disciplines het probleem aan pakken.

Voorts is kenmerkend dat men het vraagstuk niet tracht te vereenvoudigen om het geschikt te maken voor toepassing van standaard-technieken, maar juist het onderzoek uitbreidt tot alle verschijnselen die voor de oplossing van het vraagstuk relevant zijn.

Een derde kenmerk van de operationele-researchbenadering is de toepassing van modellen om een organisatie te beschrijven.

In het artikel worden twee modellen besproken. In het eerste model wordt het gegeven probleem geformuleerd met behulp van wiskundige symbolen, hetgeen is toegelicht met een voorbeeld. Een tweede type is het zogenaamde ,analoque" model, waarbij de reële situatie, die voorwerp van onderzoek is, in een model wordt nagebootst om het vraagstuk op te lossen. De schrijver geeft een voorbeeld van de bepaling van de optimale locatie van een fabriek om de transport-kosten te minimaliseren.

Het onderzoek, waarbij de operationele-researchbenadering wordt toegepast, kan worden verdeeld in 6 fasen. Deze zijn: a) de probleemstelling; b) weergave van de situatie door middel van wiskunige symbolen of een model; c) manipulaties met het model (analytisch of door simulatie); d) selectie van de optimum-voorwaarden; e) gevolgtrekkingen. Een voorbeeld is opgenomen om bovenstaande onderverdeling van het onderzoek toe te lichten.

Tenslotte merkt de schrijver op, dat als maatstaf voor de effectiviteit van deze benadering kostenoverwegingen moeten gelden.

Ba VI - 12, 19

Accountancy, juli 1967

E 641.23

\section{Methods of Estimating Consumer Preference Distributions}

Day, Professor R a l ph L. - De auteur is van mening, dat het marktonderzoek meer in betekenis toeneemt, wanneer men gebruik maakt van de middelen en theorieën, ontwikkeld in de exacte en de gedragswetenschappen dan wanneer men tracht een zelfstandige wetenschap te ontwikkelen. Dit uitgangspunt vindt men terug in de research en deze research krijgt in dit artikel de volle aandacht. Het is Day Thurstone's idee geweest een schatting te geven van de frequentieverdeling van de consumentenvoorkeur en dit idee heeft aanleiding gegeven tot verschillende praktische toepassingen met als grondslag de frequentieverdeling van de consumentenvoorkeur. Drie daarvan worden achtereenvolgens besproken. De Benson-methode behandelt de toepassing van verdelingen als een vraagstuk van praktisch onderzoek; hij bepaalt de voorkeurverdelingen direct uit gegevens die bij veldonderzoek zijn verkregen. De meer gecompliceerde Kuehn-methode gaat uit van een model, dat de analyse en interpretatie van produkttestgegevens omvat in termen van een waarschijnlijkheidsmodel van de consumentenkeuze; het berust op een schatting van het onderscheidingsvermogen van de consument. Tenslotte wordt een methode beschreven, waarbij door middel van computer simulation verdelingen en schattingen van het onderscheidingsvermogen worden verkregen. Deze methode is te verkiezen boven de Kuehnmethode en wordt aanbevolen voor die gevallen, waarbij de door de onderzoeken voorafgemaakte veronderstellingen worden ondersteund door inleidende analyses.

Ba VI - 12

California Management Review, 14-7-1967

E 641.254

\section{Maximising the Mix}

M u i r, A. - Bij het streven naar optimalisering van het goederenpakket dat een onderneming voortbrengt, is de eerste moeilijkheid het vaststellen van hanteerbare groepen homogene produkten. De selectiemaatstaf is de winstgevendheid (tenzij een produkt aangehouden wordt wegens zijn verkoop bevorderende kwaliteiten). De produkten die in een bepaalde groep worden opgenomen, moeten daarom gelijke waarden hebben voor de be- 
langrijkste winstbepalende factoren, te weten de prijs, de variabele kosten en het beslag op de produktie-capaciteit.

In bepaalde gevallen kan men ter bepaling van het meest gewenste goederenassortiment volstaan met het bepalen van de bijdrage in de dekking van de periodekosten door de bruto-winst per produktengroep, of per produktengroep per capaciteitsuur. Op grond hiervan kan men selecteren. In gevallen waarbij verschillende produktengroepen verschillende machines of andere produktiemiddelen in verschillende mate gebruiken, is lineaire programmering de beste methode. Teneinde het produktenpakket zoveel mogelijk bij de markt aan te passen, worden in het lineaire programmeringprobleem zekere marktrestricties ingevoerd.

Wanneer de oplossing gevonden is, moet echter de onderneming nog steeds proberen de verkoop van de meer winstgevende produkten te bevorderen ten koste van minder winstgevende artikelen. Men kan daartoe o.a. een beperkt aantal prijsveranderingen doorvoeren.

Lineaire programmering makkt het voorts mogelijk de invloed te bepalen van additionele investeringen, geïntegreerd in de collectiviteit van kapitaalgoederen, op de totale winst.

De waarde van lineaire programmering ligt in haar betekenis voor continuele herziening van het produktenassortiment, de prijsstructuur en de investeringen, waarbij kritieke factoren geïntegreerd in het toraal worden waargenomen.

Ba VI - 12 : E 612.511 : E 641.231.1

Management Today, juli 1967

Die organisatorische Eingliederung der Investitionsgütermarktforschung in die Unternehmung

R a d eker, F. R. - Op de markt van investeringsgoederen (produktiemiddelen) constateert de schrijver een tendens die zich op de consumptiegoederenmarkt reeds eerder openbaarde, nl. een verschuiving van een verkopersmarkt naar een kopersmarkt. Dit heeft tot gevolg dat ook op de markt der produktiemiddelen het marktonderzoek belangrijker wordt, wat door alle bedrijven in deze sector nog niet wordt ingezien. De afdeling Marktonderzoek is staforgaan, dat direct onder het dagelijks bestuur behoort te staan. Onjuist is het als deze afdeling in de lijnorganisatie wordt opgenomen in het kader van een afdeling statistiek of een verkoopafdeling. Belangrijk is een doelmatige uitbesteding van marktonderzoekactiviteiten aan hierin gespecialiseerde instellingen en schrijver noemt de volgende voordelen daarvan. 1) De grotere kennis van de specialist. 2) Voorkomen van bedrijfsblindheid. 3) Grotere mate van objectiviteit. 4) Lagere kosten. De medewerker op de afdeling Marktonderzoek dient de interne activiteiten zoals het verzamelen en interpreteren van gegevens, te coördineren en specifieke onderzoeken aan gespecialiseerde instituten over te dragen. Wil de afdeling Marktonderzoek haar werk goed kunnen doen dan moet aan de volgende voorwaarden voldaan zijn. 1) Een directe ondergeschiktheid aan de ondernemingsleiding. 2) Onbeperkte erkenning van de staffunctie van de afdeling Marktonderzoek door alle sectoren van het bedrijf en een onbeperkte ondersteuning van haar activiteiten. 3) Een schriftelijke vastlegging van de bevoegdheden van deze afdeling.

$\mathrm{Ba}$ VI - 13, 12

Industrielle Organisation, 1967 nr. 8

E 642.354

\section{The promise of Simulation in Marketing}

$\mathrm{H}$ a rold We it z - Ondanks de duidelijke toeneming van het toepassen van de simulatiemethode bij de behandeling van marketing-problemen, zijn de toepassingsmogelijkheden, voor zover in de literatuur is na te gaan, nog grotendeels ongebruikt gebleven. Na hiervoor verschillende redenen te hebben aangegeven, geeft de schrijver een indeling van de onderscheiden simulatiemodellen en een korte beschrijving van elk der drie categorieën, $\mathrm{nl}$. classificatie op basis van de doelstelling, op basis van de omschrijving van het systeem (tactisch versus strategisch) en op basis van de structurele eigenschappen. Vervolgens bespreekt hij een aantal voor- en nadelen van de simulatiemethode. Een voordeel van simulatie is dat men minder dan bij analytische benadering simplificaties behoeft te maken. Door middel van de simulatiemethode kan men relatief goedkoop experimenteren. Uit simulatie-studies kunnen vaak analytische modellen voor optimum vraagstukken worden ontwikkeld. De simulatie-taal is niet ingewikkeld. $\mathrm{Zij}$ is eenvoudiger te begrijpen dan een complex mathematisch model. Tegenover deze voordelen moet men bedenken dat deze methode ook zijn beperkingen heeft. Men verkrijgt met deze methode niet gemakkelijk optimale resultaten en het toepassen ervan kan zeer tijdrovend zijn. Wat betreft de mogelijkheden van toepassing noemt de chrijver o.m. het opstellen van een prognose van de reactie van de consument op nieuwe produkten of een prognose van het aandeel in de markt, marktspelsituaties en Input-Output analyse. Schrijver ziet voor de toekomst een veelvuldiger en intensiever gebruik van de simulatiemethode.

$\mathrm{Ba}$ VI $-15,12$

E 641.25

Journal of Marketing, juli 1967

m a b blz. 147 
A rmitage, R. Q. - Teneinde de winstgevendheid van een onderneming te handhaven moeten soms nicuwe produkten op de markt geïntroduceerd worden. Deze nieuwe produkten behoeven niet onmiddellijk maximaal voordeel op te leveren; het gaat er om wat zij zullen betekenen in de toekomst. Een onderneming dient een goederenpakket voort te brengen dat gericht is op het heden en de toekomst.

Het succes van de ontwikkeling en introductie van nieuwe produkten hangt met name af van de wijze waarop dit deel van de ondernemingsactiviteiten is georganiseerd. De schrijver geeft een uiteenzetting over een systematisch opgezette werkprocedure. De afdelingschefs worden bij het nieuwe project van het begin af aan betrokken en voldoende geïnformeerd. Met behulp van vragenformulieren en vergaderingen wordt een uitgebalanceerde waardering van het project opgesteld waarin de meningen van de betrokken chefs zijn verwerkt. Een en ander gaat volgens een methodische opzet. In alle fasen van verfijning der gegevens en uitwerkingen worden de afdelingschefs volgens deze methode bij de ontwikkeling van het project betrokken. Het resultaat is een volledig eindprodukt, een volledige analyse van de elementen die voor de productie vereist zijn, een kostenbegroting, winstprognose en een marktproef. Specialistische kennis van insiders en outsiders zijn in de project-analyse verwerkt en als zodanig wordt het aan het ondernemingsbestuur voorgesteld. $\mathrm{Na}$ goedkeuring vormt de project-analyse een werkinstructie voor elke afdeling. Nu worden ook uitgaven gedaan voor verkoopbevordering en additionele productiebenodigdheden.

De sleutel van de toekomst van de onderneming is het aantal succesvolle nieuwe projecten dat de onderneming weet te ontwikkelen. Methodische aanpak moet zo veel mogelijk mislukkingen voorkomen.

$\mathrm{Ba}$ VI -15

E 641.254

Management Today, juli 1967

\section{The six Personal Work Problems of the Managing Director}

S v e n s o n, D r. A. L. - In dit artikel worden de belangrijkste problemen besproken, die een directeur van een onderneming in zijn werk ontmoet. De schrijver onderscheidt er zes:

1. De bepalingen van de taakinhoud.

Als criterium wordt genoemd, dat de managing director zich in de eerste plaats moet richten op de beleidsbeslissingen en werkzaamheden, die van direct belang zijn voor het voortbestaan van de onderneming.

2. De relatie met de eigenaar-ondernemer.

Als de onderneming door de grootte en de complexiteit voor de eigenaar niet meer bestuurbaar wordt, zal hij een professionele managing-director in dienst nemen. Deze moet zichzelf waar weten te maken en ook het toekomstbeeld dat de eigenaar-leider en de chefs over de onderneming hadden, weten te veranderen. Hij moet een oneindig grote vaardigheid tonen in het heroriënteren van de onderneming.

3. De oude en nieuwe taken.

Wordt de directeur gerecruteerd uit de onderneming zelf, dan moet hij zich niet meer direct bezighouden met zijn vroegere werk. Zijn oude relaties mag hij echter niet verwaarlozen zonder daarmee zijn nieuwe verplichtingen tekort te doen.

4. De verhouding met de Board of Directors.

Deze relatie is afhankelijk van de situatie, waarin de onderneming zich op het tijdstip van benoeming der directeur bevindt. In tijd van crisis zal hij van de Raad vrij mandaat willen hebben. In normale perioden zal veel afhangen van de inzichten van deze Raad met betrekking tot het beleid.

5. Evaluatie van het eigen beleid.

Hiertoe zal de directeur niet genoeg hebben aan de jaarlijkse verlies-en winstcijfers, maar voor zichzelf met meer frequente overzichten moeten werken.

6. Planning van eigen opvolging.

Dit leidt vaak tot strijd met de Board, die dan soms reeds een 'kroonprins' aanwijst.

Ba VI - 16

E 642.41

Management International Review, 1967 nr 2/3

\section{The Pricing of Internal Transfers}

$\mathrm{L}$ ive se y, $\mathrm{F}$. - Bij het groter worden van een onderneming treden naast de bekende voordelen hieraan verbonden, ook nadelen op, zoals verlenging van de communicatielijnen, enz. Deze bezwaren laten zich goeddeels opheffen door de onderneming op te splitsen in kleinere zelfstandige eenheden (divisions) met een indeling naar produkten of produktgroepen, waarbij de divisionmanager verantwoordelijk is voor de winstgevendheid van zijn eenheid. Moeilijkheden kunnen zich dan voordoen als de eenheden op dezelfde markt opereren, zodat zij concurrenten zijn of indien zij een koper-verkoper relatie hebben. De 
schrijver stelt nu de vraag aan de orde welke mate van vrijheid zulk een afzonderlijke eenheid in dit laatste geval moet hebben en hoe de interne prijzen van zulke produkten worden bepaald.

Een onderzoek wees uit dat men als leveringsprijzen neemt: a) de onderhandelingsprijs, d.w.z. de prijs wordt door onderhandeling tussen partijen vastgesteld; b) de integrale kostprijs; c) de integrale kostprijs + een opslagpercentage; d) de variabele kosten; e) de marktprijs. Binnen de doelstellingen - zoals o.a. winstmaximalisatie - dient ook bepaald te worden hoe de verplichtingen tussen de eenheden liggen. Mogelijkheden zijn hier: a) de division-manager is vrij om te leveren aan wie hij wil; hij is dan volledig aansprakelijk voor de winst in zijn eenheid en niet voor een eventuele leegloop in een andere eenheid; het gevaar bestaat dat dit systeem eerder een rivaliteit dan een samenwerking tussen de eenheden tot gevolg heeft; b) de andere eenheden hebben een optie om te kopen; c) de eenheid levert een bepaald percentage (meestal 100) aan de andere eenheden. De schrijver gaat nu na wat de consequenties voor de doelstellingen kunnen zijn bij de verschillende mogelijkheden en merkt in dit verband o.m. op dat in geval van prijszetting op het peil van de variabele kosten, (de vaste kosten van de gehele onderneming worden dan bij elkaar gevoegd) de ,winst" per zelfstandige eenheid niet wordt beïnvloed door het gedrag van de vaste kosten, terwijl dit bij doorberekening op basis van integrale kosten wel het geval is. Bij de beoordeling van de mérites van beide systemen dient men na te gaan: a) de mate van beïnloeding van de vaste kosten door de leider van de zelfstandige eenheid; b) de mate van vrijheid van levering van die leider.

$\mathrm{Ba}$ VI -18

The Accountant, juli 1967

E $643.4-133.33$

\section{Netwerkplanningtechnieken I; Planning en netwerkplanning}

B osman, Drs A. en We z e ma n, Drs K. - In dit eerste van een viertal artikelen over netwerkplanning wordt aandacht besteed aan de grondslagen der netwerkplanningtechnieken en aan het karakter van planningproblemen in het algemeen.

De auteurs onderscheiden bij de planning twee stadia. Het eerste omvat de vaststelling van de doelstelling en van de wegen waarlangs men deze zou kunnen bereiken. In de tweede fase tracht men, gegeven een bepaald criterium, te bepalen welke van deze wegen de beste zou zijn. In de eerste fase worden dus mogelijke ordeningsrelaties omschreven, in de tweede fase wordt vastgesteld welke bruikbaar zijn. De keuze zal in onderhandelingen tussen de bij de planning betrokkenen worden bepaald.

Bij de netwerkplanning wordt een ordeningsrelatie weergegeven door een graph, een verzameling punten, met daartussen pijlen, die in een bepaalde richting wijzen. Deze grafische weergave wordt bepaald door technologische data, door welke de opeenvolging van de activiteiten in de tijd is vastgelegd. In de tweede fase, die dient ter vaststelling of een graph acceptabel is, wordt van de graph een netwerk gemaakt, door aan de pijlen (activiteiten) getallen toe te kennen, die de tijdsduur van elke activiteit aangeven. Door de tijdsduren te sommeren van de activiteiten, die de langste reeks opeenvolgende activiteiten in het netwerk vormen (het zgn. kritieke pad) wordt de tijdsduur van het geplande project verkregen.

In vergelijking met de zgn. Gantt-chart, een staafdiagram (de staven geven de activiteiten weer) waarin horizontaal de tijd is afgezet, geeft het netwerk een betere voorstelling van de afhankelijkheid tussen de activiteiten. De eerste gaat uit van een reeds gegeven ordening, waardoor de betekenis vrijwel beperkt blijft tot het terrein der voortgangscontrole.

Echter ook de toepassing van de netwerkplanning is aan beperking onderhevig. Bij terugkoppeling faalt deze techniek, daar zij alleen kan werken met gerichte graphen.

Met name bij de projectplanning, waar het doel eenduidig is bepaald en het aantal mogelijke wijzen van technische uitvoering klein is, is zij echter goed bruikbaar.

Het laatste deel van het artikel gaat verder in op de technische aspecten van de netwerkplanning.

Ba VI - 19

E 641.231.1

Maandblad voor Accountancy en Bedrüfshuishoudkunde, september 1967

\section{Morphologie bei der Planung neuer Produkte}

R o th e n b a c h, F. - De morphologie biedt de mogelijkheid m.b.v. een morphologisch schema de verschillende mogelijke oplossingen die bij de planning naar voren komen te onderzoeken en uit de alternatieven een keuze te maken.

Morphologisch onderzoek wil hier zeggen: een integraal onderzoek dat zonder vooroordeel alle mogelijke oplossingen afleidt. Hiertoe wordt opgesteld, een morphologisch schema. In 5 stadia komt men tot een optimaal resultaat. 1) Definitie van het probleem. 2) Opstelling van parameters, d.i. een exacte vaststelling en localisatie van alle omstandigheden die het probleem beïnvloeden. 3) Opstelling van het morphologisch schema dat in 2 of meer 
dimensies wordt opgezet. In geval van 2 dimensies worden in een plat vlak verticaal de parameters uitgezet en horizontaal de componenten waaruit de parameters bestaan. Elke rij van boven naar beneden bevat dus van elke parameter één component en geeft één mogelijke oplossing. 4) Analyse van de mogelijke oplossing. 5) Keuze van de optimale oplossing.

De schrijver geeft nu een voorbeeld van de samenstelling van een menukaart in een restaurant. De parameters zijn de diverse gangen en de componenten de gerechten die binnen één gang ter beschikking staan. Op deze wijze kan men een optimaal menu samenstellen zonder de kans te lopen een bepaalde spijs of drank te vergeten.

Ook wordt nog een voorbeeld gegeven dat ontleend is aan de techniek. Het vraagstuk betreft hier het op het juiste moment tot ontbranding brengen van het gasmengsel in de verbrandingsmotor om een zo hoog mogelijke efficiëntie te bereiken. Ook hier in principe dezelfde oplossing, waarbij door een waardering van de componenten de optimale keuze wordt gedaan.

Ba VI -19

Industrielle Organisation, 1967 nr. 8

E 641.231.1

\section{LEER VAN DE ARBEIDSVOORWAARDEN}

\section{Welvaartvaste pensioenen}

D r. L. M. va n L e euwe $n$ - Van Leeuwen schetst in dit artikel de moeilijkheden van het bedrijfsleven op het gebied van de pensioenvoorzieningen, die zijn ontstaan na de invoering van waardevaste en welvaartvaste ouderdoms- en ambtenarenpensioenen. Principiële gronden voor zodanige invoering acht hij niet aanwezig, doch de ondernemingen dienen er zich thans bij aan te passen.

De vraag is echter, op welke wijze dat het best kan geschieden. Niet met index-leningen (die inflatiebevorderend en kostprijsverhogend werken); ook niet door een verdere uitbouw van het bestaande omslagstelsel op basis van bv. het Franse pensioenpuntensysteem; wèl door een geleidelijke uitbouw van het huidige systeem van pensioenuitkeringen in het bedrijfsleven (waarbij de uitkering gekoppeld is - volgens een bepaald percentage - aan het aantal dienstjaren) tot een systeem, waarbij de pensioenrechten worden afgeleid van het in het laatste jaar verdiende inkomen.

De schrijver acht dit laatste systeem een haalbare kaart op grond van een aantal argumenten, waarvan de meest saillante zijn: het systeem geeft een rem-effect bij onderhandelingen over loonswerhogingen (hoe groter de verhoging, des te $z$ waarder weegt de pensioenlast), terwijl de "offers" gebracht worden door de actieve beroepsbevolking voor hun eigen pensioenen. Het is geen vrijgevigheid op kosten van kinderen en kindskinderen".

Ba VII - 9 Tïdschrift voor Vennootschappen, Verenigingen en Stichtingen, 1967 no. 9 E 262.111

\section{Fresh approaches to the skills shortage}

In het augustusnummer van „Factory” wordt een artikel gewijd aan het probleem van het tekort aan geschoolde arbeiders. Hierin worden aan de hand van in een zestiental bedrijven gevolgde methoden suggesties gedaan om het gestelde probleem tot een oplossing te brengen, zonder gebruik te maken van de traditionele manieren als omscholing van arbeiders, het trainen van de arbeiders etc. Deze „frisse” ideeën omvatten:

Het geschikt maken van het werk voor ongeschoolden door middel van gedetailleerde instructieboeken. Het geschikt maken van minder-geschoolden voor geschoolde arbeid met behulp van audio-visuele hulp; t.v.- en bandrecorderinstructie tegelijk. Het bijeenbrengen van schaarse geschoolde arbeid, door een andere organisatie van het produktieproces. Het teniet doen van het onjuiste onderscheid tussen mannelijke en vrouwelijke geschoolde arbeid. Daarbij moeten de werktijden voor vrouwen met schoolgaande kinderen aantrekkelijk worden gemaakt en de fabriek nabij een winkelcentrum zijn gevestigd. Het gebruik maken van het geschoolde arbeiders-overschot ,elders". Als voorbeeld wordt hier gebruikt, de vestiging van een montage-afdeling in Hongkong, waar geschoolde arbeid aanwezig is, en tevens de lonen beduidend lager zijn dan in de Verenigde Staten. Het halen van geschoolde arbeiders uit ,omliggende" werkzaamheden, tevens het creëren van een nieuwe, beter betaalde specialistische functie. Het verdelen van de werkopdrachten in kleine stukjes, zodat minder-geschoolden het werk kunnen doen. Het gebruiken van een automatische bediening om het gebrek aan geschoolde krachten op te heffen. Het vervangen van werkmethoden, welke geschoolde arbeid vereisen door methoden waarbij machinale arbeid mogelijk is. Het verbeteren van het arbeidsklimaat om geschoolde arbeiders te behouden.

Een drietal andere aanbevelingen sluit deze rij van Amerikaanse voorbeelden ten aanzien van het gestelde probleem.

$\mathrm{Ba}$ VII - 7

Factory, augustus 1967

E 641.212.3: 4 